\title{
EUROPEAN URBANIZATION - BETWEEN STRENGTHS AND RISKS
}

\author{
Marcela-Cornelia Danu \\ "Vasile Alecsandri” University of Bacău \\ marceladanu@ub.ro
}

\begin{abstract}
On the European continent, urban population, representing a significant segment of the market, with features specific to a particular model of purchase, consumption, lifestyle, etc. , has the potential for growth. The possible effects of this increase (strengths or risks), include: increasing opportunities for employment, increasing level and structure of demand for consumer goods and, in conjunction, of the level and structure of supply, raising of the standard of living, changing requirements and personal taste level population, increased interaction, socializing, psycho-social conversions on the recently urbanised population as well as for the people there, etc. but also the increase in demand for land areas intended for dwellings, commercial premises and hence reducing spaces with vegetation, increasing the degree of concentration of the population in a small grounds, effects on air quality, etc. This study highlights dynamic and interdependent effects of European urbanization on the human population, businesses, and the environment.
\end{abstract}

\section{Keywords}

urban population; human development; strengths; risks; macroeconomic effects; effects on individual; effects on the environment

\section{JEL Classification}

J11; O15; O18; O44; R11; R12

\section{Urbanization in actuality- determinants and prospects.}

Europe is among the most urbanized continents, with approximately $75 \%$ of the urban population [Expansiunea urbană în Europa, Agenţia Europeană de Mediu, Copenghaga, Raportul nr.10/2006]. Over 1/4 of the territory of the EU is at present urban use. The differences are, however, essential, so if in Iceland, Sweden, Netherlands, United Kingdom, Denmark, Belgium, Luxembourg, Malta, the share of urban population in the total population is very high, however, in others, such as Greece, Ireland, Poland, Slovakia, Slovenia, Croatia, Romania, Bosnia and Herzegovina, Albania, Moldova, it drops to $60 \%$ and $50 \%$.

\section{Table 1 Degree of urbanisation in Europe}

\begin{tabular}{|l|c|c|l|c|c|}
\hline \multirow{2}{*}{ Country } & \multicolumn{2}{|c|}{ Urban population (\%) } & \multirow{2}{*}{ Country } & \multicolumn{2}{c|}{ Urban population (\%) } \\
\cline { 2 - 3 } & $\mathbf{2 0 0 5}$ & $\mathbf{2 0 1 2}$ & & $\mathbf{2 0 0 5}$ & $\mathbf{2 0 1 2}$ \\
\hline Albania & 46.8 & 54.5 & Macedonia & 59.1 & 59.4 \\
\hline Andorra & 90.3 & 86.7 & Malta & 93.6 & 95 \\
\hline Austria & 66.5 & 67.9 & Moldova & 43.2 & 48.4 \\
\hline Belarus & 72.4 & 75.5 & Monaco & 100 & 100 \\
\hline Belgium & 97.3 & 97.5 & Montenegro & 62.2 & 63.5 \\
\hline Bosnia and Herzegovina & 45.3 & 48.8 & Netherlands & 80.2 & 83.6 \\
\hline Bulgaria & 70.2 & 73.7 & Norway & 77.5 & 79.7 \\
\hline Croatia & 56.4 & 58.1 & Poland & 61.5 & 60.8 \\
\hline
\end{tabular}




\begin{tabular}{|l|c|c|l|c|c|}
\hline Cyprus & 69.4 & 70.7 & Portugal & 57.6 & 61.6 \\
\hline Czech Republic & 73.7 & 73.4 & Romania & 52.8 & 52.8 \\
\hline Denmark & 85.9 & 87.1 & Russia & 72.9 & 74 \\
\hline Estonia & 69.4 & 69.5 & San Marino & 94 & 94.1 \\
\hline Finland & 82.9 & 83.8 & Serbia & 54.4 & 56.7 \\
\hline France & 81.6 & 86.4 & Slovakia & 55.6 & 54.7 \\
\hline Germany & 73.4 & 74.1 & Slovenia & 50.5 & 49.8 \\
\hline Greece & 60.3 & 61.7 & Spain & 76.7 & 77.6 \\
\hline Hungary & 66.4 & 69.9 & Sweden & 84.3 & 85.4 \\
\hline Iceland & 93 & 93.8 & Switzerland & 73.5 & 73.8 \\
\hline Irland & 60.5 & 62.5 & Turkey & 66.8 & 72.5 \\
\hline Italy & 67.6 & 68.5 & Ukraine & 67.8 & 69.1 \\
\hline Latvia & 68 & 67.7 & UK & 79 & 79.7 \\
\hline Liechtenstein & 14.7 & 14.3 & Europe & $\mathbf{7 1 . 6}$ & $\mathbf{7 3 . 1}$ \\
\hline Lithuania & 66.6 & 67.2 & UE 27 & $\mathbf{7 2 . 6}$ & $\mathbf{7 4 . 1}$ \\
\hline Luxemburg & 83.9 & 85.7 & & & \\
\hline
\end{tabular}

Source: http://hdr.undp.org

In general, urban expansion occurs when the rate of conversion and utilization planning, urban purposes exceeds the population growth rate in a given area in a given period of time. Recent studies show that the European cities has increased over the past decade with growth over 5\%, equivalent to 3 times the area of Luxembourg. The strongest urban expansion has been manifested in countries or regions with high density of population and very large development-Belgium, Netherlands, Germany (South and West), Italy (Northern), France (Paris) as well as in countries with rapid economic growth, Ireland, Portugal, Germany (East), Spain (Madrid).

Urban expansion has been determined, on our continent, too by the regional development policies promoted at EU level - to the deficient regions were targeted funds from the EU structural and cohesion funds, to develop and modernize infrastructure; with increasing number of urban population in large cities of the continent began to develop too the areas adjacent to the small towns or rural areas, more developed along the corridor and along the coastal areas in connection with river valleys.

Among the generals determinants of the ever-expanding urban phenomenon is micro and macro socio-economic trends: increase the quality of the transport systems, the rising price of land, raising residential preferences, European and national demographic trends, the traditions, the cultural customs, the attractiveness of urban areas, and last but not least, the increasing mobility of the population in the area.

One dimension of urbanization is metropolisation. This is manifested both in the centers of the global economy-(USA, Western Europe, Japan), as well as in less advanced countries, where urbanization demonstrates the weakness of medium or small cities. At the same time, the hierarchical order of the principal agglomerations of the planet is changing. In 1875, London was by far the largest urban unit in the world, other British cities is among the 5 top 20 urban agglomerations of the world [www.ccasp.ase.roe-city, Aspecte semnificative ale competitivităţii şi dezvoltării urbane la nivel european].

Another trend is the growing, twice the space for a person, compared to 50 years ago. Since the 1980s the built-up areas in many countries in Western and Eastern Europe has increased by $20 \%$ while the population grew by only $6 \%$.

In Romania, due to the large socio-economic differences between rural and urban life, continues the phenomenon of migration of the population of the city. In cities, the 
high-income class movement to residential suburbs, while crowded areas remain inhabited by people's class. In the suburbs are built villas, swimming pools, tennis courts, etc., while in the big districts appear opportunities for large stores. Possible that, in the future, we are witnessing the movement of population from the less developed the historical regions (Moldova) to the most powerful developed countriesTransylvania, Banat.

\section{Strengths of the urbanization - An European perspective}

It is estimated that by the year 2020. 80\% of Europeans will live in urban areas, and from the 46 countries of the continent, in 7 of them share of urbanization will be over $90 \%$. The logical consequence is the need for increased demand of land affected housing, commercial spaces, etc. Witnessing to the phenomenon of urban sprawl in Europe; the phenomenon, however, is different from one country to another, from one region to another; causes changes of substance in lifestyles and consumption patterns at the scale of the continent.

Although urbanization generally increasing concentration of population and economic life, it brings some complaints, especially from the point of view of the quality of the natural environment, there are a number of advantages and opportunities that this phenomenon creates it; it was found that the use of the territory and the consumption of different energy forms tend to be lower in urban areas than in areas with a dispersed population; waste management and urban water management enjoys the benefits of economy of scale. For example, analyzing consumer spending for food and non-alcoholic beverages for a few European countries [www.eurostat.com] (Fig.1) we note that, in most cases, including the EU average, they are higher in areas with a dispersed population compared to areas with dense population. Another aspect, which emphasizes, is that of the absolute size of this type of expenditure, which reflects both population inclination to consume more or less of the goods (having the determination the certain consumer traditions, a certain style of life, culture, mentality) and the size of the prices for those products which meet the basic needs of the individual. The situation of ex-Communist countries-Bulgaria, Latvia, Poland, Slovakia, Estonia illustrates both a higher level of expenditure on food and nonalcoholic beverages compared to all the other countries in the EU or outside the EU (at that time) as well as the reality that areas with small population spend more buying the food goods.

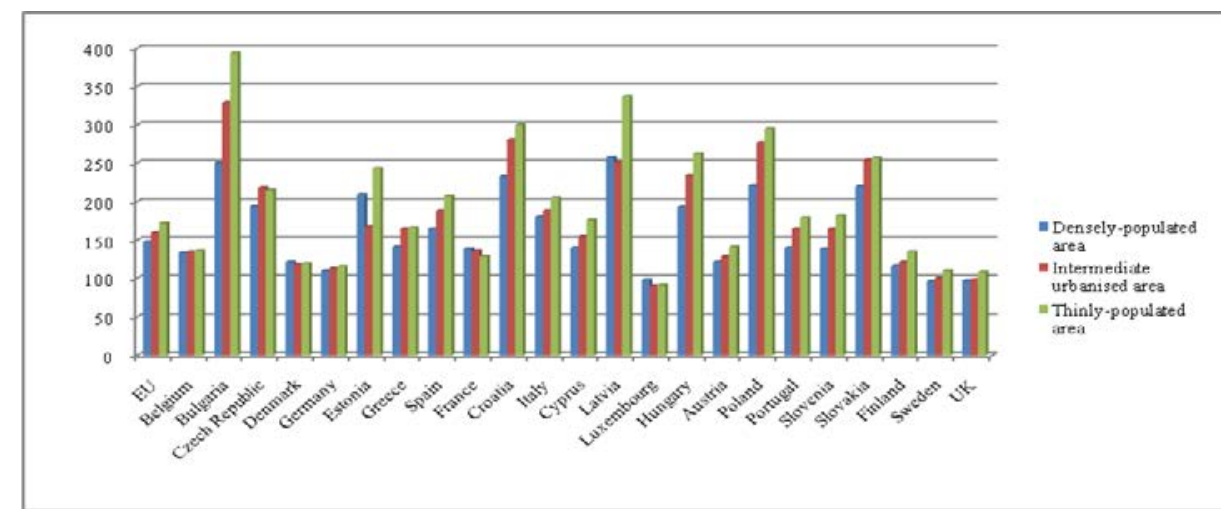

Figure 1 Consumption expenditure by degree of urbanisation - Food and nonalcoholic beverages 
In terms of transport expenses [www.eurostat.com] (Fig.2), for the same countries analyzed, we see that, they are too higher in areas with a dispersed population compared to areas with dense population, in most cases. This confirms the EU average but also developed countries - Luxembourg, United Kingdom, Denmark etc., or ex-Communist countries-Estonia, Croatia, Hungary, etc. The main determinants of this situation are: motivation of transport, frequency of transport movements, distance, travel price, - different in the case of developed countries compared with the ex-Communist countries.

Anyway, beyond the expenses that the population makes them with the purchase of these goods and services, related to income levels, resulting from the consumption of such goods and, further, the inputs (human, financial, material, informational), higher in the low population density compared to the concentration of population area.

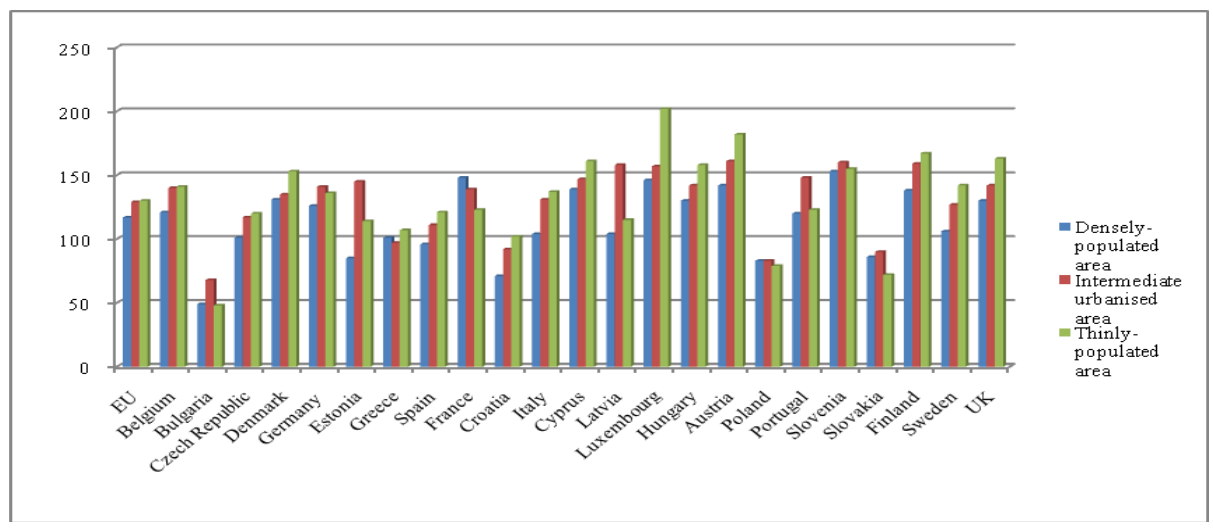

Figure 2 Consumption expenditure by degree of urbanisation - Transport Source: www.eurostat.com, 26.06.13

A problem that is getting the attention of European decision makers is mobility and accessibility, as essential factors of the territorial cohesion of Europe. The number of miles of european land transport will increase during $1995-2030$ by $40 \%$. Degree of urbanisation of the population new entrants into the Eu is not at the level of the other; the degree of congestion of the road grew strong by the year 2010 and the associated costs increased by $1 \%$ of EU GDP. Development of local, national and European infrastructure will stand in decision-makers attention in the field of regional development, regarded as the basic premise itself local, regional and European economic development.

Another advantage of urbanization is increased efficiency of activities in urban areas compared with those from areas with a dispersed population [wgbis.ces.iisc.ernet.in/energy/, Urbanization - impacts]. The supply of electricity, water, gas etc. services is less expensive than in areas with low population density. Therefore, lower cost to creating, to maintain, to supply of those utilities, defrayed by the Community, Government, population. Also, research programs in these fields and recycling are less, or not at all possible in areas with low population density. Another coordinated of the efficiency, is the use of space: in cities, dwelling blocks save land that can be end industrial use - creative industrial jobs, either commercial - covering 
consumer needs of the population, be it leisure, relaxation, green spaces, parks, playgrounds for children, etc. - covering such needs and preserving the natural environment.

Access to services for the European population is much higher in urban areas than in rural villages. Educational services - in all forms, health, social, cultural, transport services - are more available to the urban population than rural population. Urban life style provides, in most cases, more comfort, convenience and possibilities of direct communication and relationship of much larger, faster, and less time consuming.

From the perspective of the services suppliers, as a result of a great request, expressed in a high-density area, the supply continually adjusts, both in terms of quantity and quality, diversification of product range of tangible and intangible, or according to preferences and dynamic requirements of the urban population. The increase in volume of supply involves using the best possible production capacity, requiring additional labour and, on this basis, the reduction of unemployment. As a result, the advantage is so urban consumer and interconditional of the companies, of the community, of the national economy.

The social integration of individuals, increase the level of understanding, knowledge, tolerance, acceptance of different cultures and, on this basis, the decrease of psychosocial risks, can be attributed living ,arround”, in which individuals can identify and exploit their desired values, intellectual and relational potential etc. Great human communities in Europe can harness the advantages of economies of scale, can attract national financial resources, European or international and may be used in a more efficient way these resources as compared to the situation in smaller communities where the number of beneficiaries of programmes is small.

\section{Risks arising from the increase of urbanization}

Although, in most cases, we look at the competitive risk it assumes firms in doing business, one of the risks of the individual supports its existence, is the competitive risk. In this situation, it's about fighting for a better existence of individuals from rural areas eager to start another life in urban area, wanted to be better. [wgbis.ces.iisc.ernet.in/ energy/, Urbanization - impacts]. Due to lack of education, many of whom, entering the labour market, failing to find jobs, decent housing, and, further, reaching the outskirts of large towns, dwelling in unsanitary, unseemly living conditions, lack of security, severe poverty. The lure of the city turned into a risk they have assumed, and, unfortunately, 'they have incorporated in their lives'. Moreover, from here derives its psycho-social problems of individuals and the social risks covered by the community members.

Another risk, as determined by the increase in the number of urban population, is a major social risk - the unemployment. Once the number of the population of a community increases, the demand for labor has increased the risk that the newcomer population in that environment, don't find employment, is very high. Further, it is influenced the achievement of risk of poverty whose resolution may not be immediate, being determined to the growth and development of urban business environment at a pace higher than the growth rate of the joiner population.

Pauperization and privations of all kinds creates conditions for the installation of criminal phenomena, many of them associated with the underground economy, macrosocietal risk.

One of the risks the urbanization creates and/or develops, is the risk of pollution. Most of the European cities solved issues related to utilities, however, risk of pollution manifested in every form, is increased - the pollution of air, water, noise 
pollution and, in some cases, visual pollution, are realities of the present. Industry and automobiles are 'guilty' of the creation of this risk. For industry, the European decision - makers taken legislative, financial measures, to reduce pollution. As regards automobiles, increasing the standard of living of the majority of the European population, multiplying the number of cars, turns into several types of risk, the most serious and most perennials - air pollution and the increase in consumption of motor fuels, associated with diminishing oil reserves.

The rise in consumption of fuels is attached to an increasing number of motor vehicles. Thus, in Europe, the number of holders autoturime at 1000 persons increased in 2010 compared to 2003, in Austria, from 499 to 529, in Bulgaria, from 295 to 345, in Finland, from 433 to 538, in Luxembourg, from 638 to 665, in Romania, from 142 to 201 [http: //data.worldbank.org/indicator/]. The biggest increase have recorded ex-communist states and the smallest increases or even decreases in the number of vehicles have recorded the developed States.

At the level of the european continent, consumer spending for housing, water, electricity, gas and other fuels are, in most situations, larger in areas with a high population density compared to areas with low density (Fig.3). The explanation is derived from the much larger number of users, in the first case, compared to the second. Aside from this situation, notable is that consumer spending with utilities, in absolute numbers, much greater in countries like Bulgaria and Estonia compared with other developed countries on the continent. This situation may be determinants: high consumption of energy products, non-performing technologies, causing losses of energy, high price of these products/services, lean scrapper saving energy resources, etc.

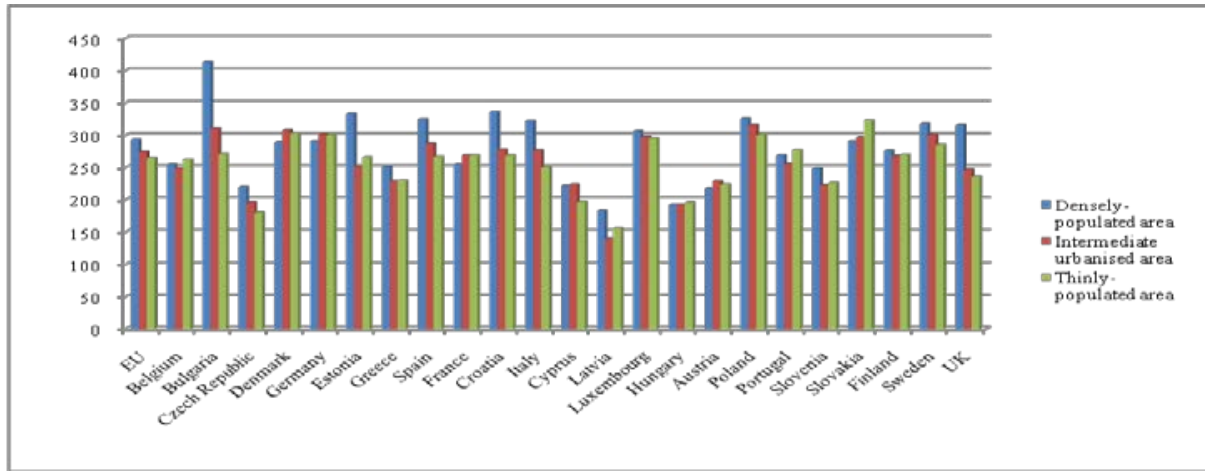

Figure 3 Consumption expenditure by degree of urbanisation - Housing, water, electricity, gas and other fuels

Source: www.eurostat.com, 26.06.13

In addition, propagated risks are medical risk, affecting individuals ' healthrespiratory diseases, allergies, etc., and the natural environment, unable to be returned quickly.

Temperature rise in urban areas, due to the increase in population, housing, apartments, industries, is another type of anthropic risk with effects of both the population and businesses or the natural environment.

The quantity of precipitation increases, amid changes in the water cycle in nature, is a pure risk with anthropogenic determination, specific too areas with concentrations of 
population. Expansion of cities means the transformation of hydrographic networks and as a result, changes in the magnitude and frequency of floods. That risk has made their presence felt on the european continent, causing both loss of life, damage to human health (pandemic) and material losses.

Another pure risk with anthropogenic determination, favored by urbanization, including the continent of Europe, is the destruction of plant and animal habitats. Urban growth tends to change, to overcome the original territorial limits: it multiplies and broadcast at the same time, the types of interrelated risks [Urcan I., Fenomene și procese hidrice de risc în mediul urban]. Carrying out a risk multiplier effects induced in urban centre and disruption the overall functioning of a city. A risk highlight the vulnerability of social organisation which includes all forms of urban and territorial organization. Cities are places where man has transformed the nature of the surface vegetation, paved and covered, are burying riverbeds, creating climates closed and realizing huge artificial transfers of energy and water.

The impossibility of communication network infrastructure, spatial arrangement of urban territory-to sustain a growing population, the need to involve additional costs for reconfiguring the urban space.

\section{Solutions to mitigate the 'negative urbanization'}

The vision of urban development at EU level, which brings together environmental and social considerations in the context of territorial planning policies, is considering obtaining positive effects resulting in:

- $\quad$ Policy coherence in all phases of the process;

- Expanding cooperation between agencies at all levels of responsibility;

- efficient use of structural and cohesion funds at Eu level linked with environmental regulations in order to mitigate and limit urban sprawl;

- Minimization of mistakes and failures that result in urban expansion market, in particular towards the escalation of prices of land and housing;

- Collection and dissemination of good practices in relation to the development of compact cities;

- $\quad$ Provision of green spaces in urban areas.

To conserve the natural environment are necessary behavioral changes of people and firms, transposed into the individual and organizational decisions. At Eu level, these decisions are reflected in the policies, strategies and tactics applied in the framework of national and European environment.

European countries have understood that by investing now in energy efficiency can best harness the existing production capacity, it can allocate founds for future investment, it can reduce pollution.

Efficient use of water can minimize a possible future crisis.

Also, joint actions and co-ordinated, effective use of resources to promote recycling and reusing, can reduce the quantity of waste.

The cities have great opportunities to use organic waste as compost, waste water in agriculture, inorganic wastes into reusable materials. Such actions involve the use of eco-efficient manpower so unemployment, improving living conditions.

It is also necessary to apply new technologies, what determines the default, raising, scientific research and technological development, geared towards this direction, beneficial in the long-term.

The mission of the national entities is to promote recycling and re-use of wastes, both with the support of the industrial business environment and human communities, with 
the support of private initiatives, etc. European Governments have a central role in the promotion and implementation of risk minimization programs with anthropogenic effects on the natural environment. To these are added, too the international community to supervise, monitor and promote eco-efficient technologies [www.unu.edu, Urban environment consumption]. The proposed objectives are:

- $\quad$ the setting of consumption standards in the framework of national policies;

- development and implementation of sustainable environmental technologies for both the poor and the rich;

- waiving taxes and restructuring subsidies, in order to transfer them from consumption that promotes human development from consumption that affects the quality of the natural environment;

- $\quad$ increasing the role of information, education, and environmental protection;

- strengthening international mechanisms to assess the environmental impact of consumption;

- creating organisations to defend the consumers ' rights, environmental protection, poverty eradication, to equality between the sexes, the rights of children.

- $\quad$ think globally but act locally and globally - should become a reality.

\section{Conclusions}

European urbanization is an irreversible process; its dimensions will vary in time and space, as determined by the living conditions promised by urban entities, and, moreover, of the level of development of the country in which the urban area in question. It is desirable to stop the phenomenon? In a situation in which the urban environment made available to individuals and firms strengths and advantages that a concentrated space they can offer lower cost, it would seem that, from this angle, increasing urbanization does not produce than positive externalities. However, the plethora of negative effects, it generates a chaotic, spontaneous urban development, at random, it is not desirable. What needs to be done is a proper urban planning, respecting the natural potential of the area and enhancing the interests of consumers and those of companies. Furthermore, the economic development of the rural environment should provide opportunities for a civilized, decent life and the temptation of seeking an unknown environment, in many cases, impossible to surmount risks specific to them.

\section{References}

Aspecte semnificative ale competitivităţii şi dezvoltării urbane la nivel European, available on www.ccasp.ase.roe-city.

Danu, M.C. (2001), Riscul în afaceri, Editura Plumb, Bacău.

EUROSTAT (2013), available on www.eurostat.com.

Expansiunea urbană în Europa (2006), Agenţia Europeană de Mediu, Copenghaga, Raportul nr.10/2006, available on www.eea.europa.eu/ro.

Sasu, C. (1998), Marketing internațional, Editura Polirom, Iași.

The World Bank Data (2013), available on http://data.worldbank.org/indicator/ IS.VEH.PCAR.P3/countries. 
Urban environment consumption, available on http://riscurisicatastrofe.reviste .ubbcluj.ro/

Urbanization - impacts, available on wgbis.ces.iisc.ernet.in/energy/. 